\title{
Análise das Mudanças no Número de Ocupados na Indústria Agroalimentar Brasileira ${ }^{1}$
}

\author{
Pablo Murta Baião Albino² e Marcelo José Braga ${ }^{3}$
}

Resumo: A partir da constatação da importância da indústria agroalimentar (IAA) brasileira como geradora de emprego, o presente trabalho analisou a variação no número de pessoas ocupadas nesta indústria no período de 1996 a 2012. Mediante a análise shift share (SSA) foram verificados quais efeitos são os responsáveis pelas mudanças no número de ocupados. Os efeitos utilizados no trabalho provêm das versões mais modernas e completas da SSA, de modo que foram analisados os efeitos nacional, estrutural, competitivo de mercado e competitivo de especialização, bem como a decomposição homotética e residual de cada um desses. O trabalho levou em consideração as regiões Sul e Sudeste, com exceção do Espírito Santo. Ao mesmo tempo, a base de dados também foi segmentada de acordo com os setores de atividades que formam a IAA. Os resultados encontrados indicam que o número de ocupados da IAA variou devido ao efeito nacional, ou seja, seguiu a corrente da indústria nacional, sem apresentar qualquer diferencial na sua estrutura ou na sua estratégia competitiva que pudesse ser identificada nesta análise.

Palavras-chaves: Indústria agroalimentar; Competitividade; Pessoal ocupado; Análise shift share.

Abstract: Starting from the perception of the Brazilian food industry (IAA) importance
as a job generator, this work analyses the variations of the number of employees in this
sector from 1996 to 2012. By applying the shift share analysis (SSA), it was possible to
verify which effects are responsible for the changing number of employees. The effects used
in this paper were provided by the most complete and modern versions of the SSA, and
the national, structural market competitive and specialized competitive effects, as well as
homothetic decomposition and residual of each one. This paper took into consideration
Southern and Southeastern regions of Brazil, except Espirito Santo. The database was also
segmented, covering sectors that compose the IAA. The results indicate that the number
of employees at IAA fluctuated because of the national effect, in other words, followed the

1. Data de submissão: 9 de dezembro de 2014. Data de aceite: 15 de janeiro de 2016.

2. Universidade Federal de Viçosa. Viçosa, Minas Gerais - Brasil. E-mail: pablo.albino@ufv.br

3. Universidade Federal de Viçosa. Viçosa, Minas Gerais - Brasil. E-mail: mjbraga@ufv.br 
national industry's flow without presenting any other differential in its structure or competitive strategy, which could be identified in the current analysis.

Key-words: Food industry; Competitiveness; Workforce; Shift share analysis.

DOI - http://dx.doi.org/10.1590/1234-56781806-9479005401005 Classificação JEL: A12, O14, J01, J11, J24.

\section{Introdução}

A geração de empregos vem sendo tema recorrente no cenário mundial. A Comissão Econômica para a América Latina e o Caribe (Cepal) aborda o tema chamando atenção para a participação do estado na busca de sua legitimação, na variação na taxa de participação da população economicamente ativa (PEA), no ritmo de criação de postos de trabalho, no perfil dos trabalhadores e na importância de manter o crescimento econômico elevado com equidade (BAUMANN, 2008). No Brasil não é diferente, no qual a geração de emprego, sua qualidade, nível salarial, a intensidade de mão de obra dos setores e a redução de postos de trabalho vêm sendo abordados periodicamente por vários autores (BARBOSA, 2012; BARRETO et al., 2010; FILHO, CABANAS e KOMATSU, 2014; FILHO, SCHUMACHER E REICHERT, 2011; MONTE, RAMALHO e PEREIRA, 2011; SILVA e BATALHA, 1999).

Historicamente, o Brasil tem vivenciado importantes mudanças na sua estrutura de emprego. A partir da década de 1990, a economia brasileira passou por transformações estruturais, com uma nova dinâmica no perfil de qualificação e na faixa etária do trabalhador, aumento dos empregos protegidos e maior inserção das mulheres no mercado de trabalho que afetaram a estrutura produtiva e, consequentemente, indu- ziram mudanças na estrutura do emprego, principalmente com redução das ocupações informais (BARBOSA, 2012).

Logo após a crise mundial que tem início em agosto de 2007, o emprego gerado pela indústria sofre diminuição $(-2,2 \%)$, enquanto o emprego público aumenta 4,8\% entre 2008 e 2009 (BARBOSA, 2012). Em resumo, o crescimento da economia brasileira da última década foi puxado pelo crescimento do consumo, porém sem o acompanhamento da produtividade (FILHO, CABANAS e KOMATSU, 2014). O Ipea aponta a redução da taxa de desocupação em 2012, porém esta taxa retoma os $7,9 \%$ no primeiro trimestre do ano seguinte, indicando que este é um emprego temporário (LEITE et al., 2015).

Neste contexto, a indústria agroalimentar (IAA) tem um papel importante, tanto no processamento dos produtos do meio rural quanto na geração de emprego (FISCHER e SCHORNBERG, 2007). Os produtos da IAA representaram $10,2 \%$ do Produto Interno Bruto (PIB) do Brasil em 2014 (ABIA, 2014). Além da crescente geração de empresa, o setor também gera um saldo comercial superior ao criado pelos demais setores da economia (ABIA, 2014). O faturamento da IAA em 2014 somou 525,8 bilhões, desempenho que coloca o setor na primeira posição com o maior valor bruto de produção da indústria de transformação (ABIA, 2014). A IAA vem aumentando 
o número de empregos gerados, tendo passado de 1.412 milhões em 2008 para 1.660 milhões em 2014 passando a ser responsável por $20 \%$ do total de empregos gerados na indústria de transformação. Seu crescimento foi de $17 \%$ neste período, enquanto o total da indústria de transformação cresceu 11\% (ABIA, 2014).

Quando observado o número de pessoal ocupado, a partir dos códigos de atividades, é possível perceber que a indústria de transformação tem grande relevância no Brasil. Este segmento é o segundo mais importante, atrás apenas do setor de automóveis. Dentro da indústria de transformação encontra-se o setor de fabricação de produtos alimentícios (CNAE 10) e bebidas (CNAE 11) que, juntos, foram responsáveis por $20 \%$ do pessoal ocupado em 2007 (1.409.977) e 21\% em 2012 (1.799.527), sobre o total de pessoal ocupado da indústria de transformação. A IAA apresentou, entre 2007 e 2012, uma taxa de crescimento médio de $78 \%$. É verdade que este crescimento foi inferior ao obtido pela indústria de transformação no mesmo período, porém, a IAA indica sua importância a respeito do número de pessoas ocupadas (Tabela 1).

Frente a estes dados o número de pessoas ocupadas na IAA pode ter crescido devido às transformações estruturais como o perfil de qualificação, a faixa etária da mão de obra e a maior inserção das mulheres no mercado de trabalho (BARBOSA, 2012). Por sua vez, Barreto et al.
(2010) apontam para as restruturações tecnológica, organizacional e produtiva como causas para as transformações na estrutura do emprego no Brasil entre 1994 e 2004 e, a partir de 2004, para os movimentos de demanda setorial. Ao mesmo tempo, outros autores apontam para a busca por competitividade e inserção no mercado externos como efeitos responsáveis pelas mudanças na estrutura do emprego a partir de 2004 (FILHO, SCHUMACHER e REICHERT, 2011).

Ainda com esta expressiva participação na geração de pessoal ocupado encontra-se um número reduzido de trabalhos que abordam a IAA e seu potencial na geração de emprego. Neste sentido, o objetivo do presente trabalho foi analisar a variação do número de pessoas ocupadas gerado pela IAA e identificar os fatores que afetam o mesmo tendo em vista os setores de atividades e as regiões. Com isso, seria possível identificar os setores mais relevantes dentro da IAA bem como os efeitos que impulsionam a geração de pessoal ocupado, permitindo uma atuação precisa das políticas públicas.

Desse modo, o presente trabalho está estruturado em cinco partes, sendo elas a introdução, o referencial teórico - no qual é abordada a competitividade e o número de pessoas ocupadas como variável de medida - a metodologia - trecho que apresenta a análise shift share (SSA), o banco de dados e as variáveis adotadas - os resultados e discussão e finalmente, as considerações finais. 


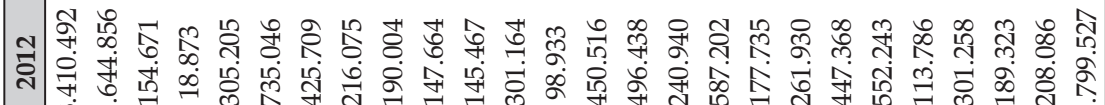

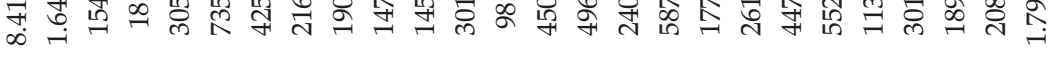

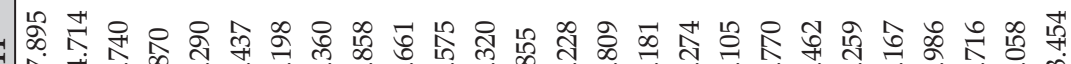

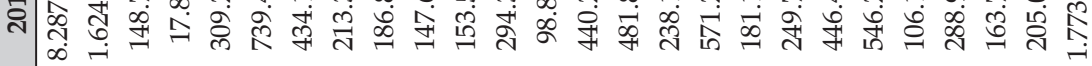

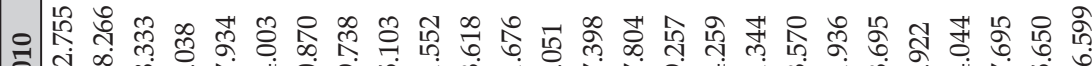

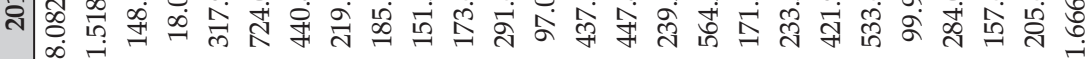

วิ

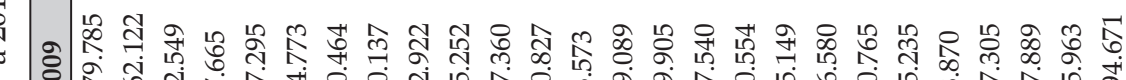
仓ิ

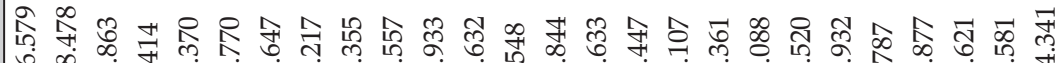

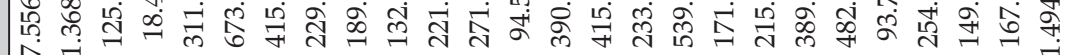

के \&

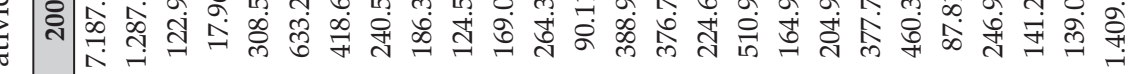
ขั 


\section{Fundamentação teórica}

\subsection{Número de ocupados e competitividade na IAA Brasileira}

A importância de um setor industrial pode ser medida pelo número de empregos que ele gera, por sua participação no Produto Interno Bruto (PIB), por sua posição na cadeia da qual participa ou por sua estrutura competitiva.

A preocupação com o emprego no Brasil ganhou importância nos anos 1990, período marcado pela abertura comercial, a intensificação do comércio internacional e pelas mudanças do regime de câmbio, que introduziram um choque de modernização e competitividade na economia brasileira com importantes efeitos sobre a produção, renda e emprego (SESSO FILHO et al., 2010).

A competitividade é uma preocupação dos governos e das empresas que buscam continuamente serem mais competitivas (BID, 2001). A competitividade está relacionada com a industrialização e a sustentabilidade do crescimento econômico (LAMONICA e FEIJÓ, 2011).

Neste sentido, Krugman (1994), afirma que, se uma empresa não é competitiva, sua posição é insustentável no mercado, ou seja, a menos que melhore sua estratégia e funcionamento, esta organização deixará de existir. A definição de competitividade de um país está relacionada com a capacidade de posicionar-se nos mercados mundiais via exportação e captação de investimentos estrangeiros diretos, além de desenvolver um atrativo para as empresas locais e estrangeiras, conforme apontam Lópes et al. (2009). Este argumento reforça a afirmação de Krugman e deixa clara a importância da competitividade para as empresas. Por sua vez, os autores argumentam que ser competitivo para as empresas significa estar presente nos mercados, obtendo benefícios, consolidando sua presença e sua capacidade de produzir bens e serviços que são demandados neste mercado (LÓPEZ, MÉNDEZ e DONES, 2009). Além disso, estudos que abordam a competitividade põem de manifesto que o potencial de crescimento futuro das regiões e suas empresas dependem do favorável que sejam as condições de competitividade (MURILLO e MUSIK, 2005). Na verdade, as regiões e os setores de atividades que dispõem de capacidade tecnológica comparativamente alta para seus níveis de receita são capazes de crescer mais rapidamente comparados aqueles que não dispõem desta vantagem (BID, 2001).

O funcionamento da economia de mercado tem como norma geral o emprego do capital e do trabalho, fatores que afetam diretamente a competitividade das organizações. Neste sentido, o governo exerce importante papel no que diz respeito à geração de emprego devido a sua abrangente e articulada intersetorialidade. O Estado pode atuar como empregador ou como promotor do emprego através das políticas públicas (POCHMANN, 2008). Esta atuação pode afetar o tipo de ocupação da força de trabalho.

No Brasil, os estados costumam oferecer benefícios como espaço físico, infraestrutura ou mesmo isenção de impostos para atrair as indústrias e gerar emprego em regiões específicas. Esta é uma das políticas evidentes no País que pode estar afetando a geração de emprego na IAA.

O Brasil presenciou, na década de 1990, uma exportação de empregos do setor industrial. Este fato se deu em decorrência das mudanças tecnológicas, da maior presença das importações com aquisição de bens e serviços de fora do País, o que destruiu postos de trabalhos internos e criou emprego no exterior (POCHMANN, 2008; SESSO FILHO et al., 2010).

No período de 1996 a 2012, a economia brasileira experimentou diversas transformações que afetaram o emprego na IAA. Devido à disponibilidade de dados e a relevância deste momento, o presente trabalho aborda a variação do número de pessoas ocupadas em dois momentos (1996-2007 e 2007-2012), para então identificar que fatores foram responsáveis pela variação do emprego na indústria agroalimentar brasileira neste período.

O período de 1994 a 1998 teve como características principais o regime de câmbio fixo e a valorização da moeda nacional, com déficits da balança comercial. A partir de 1999 teve lugar a 
desvalorização cambial, e o regime foi modificado para câmbio flexível, com melhora da balança comercial (SESSO FILHO et al., 2010).

Em resumo, durante a década de 1990, as empresas brasileiras passaram por um processo de adaptação e modernização no qual ajustaram seus quadros de funcionários, investiram em equipamentos, adequaram custos e alteraram a composição de produtos (BAUMANN, 2008). A implementação do sistema de metas de inflação e do regime de câmbio para flutuante, em 1999, coincidiram com a elasticidade do emprego, ou seja, com o crescimento econômico e na criação de emprego, rompendo com o ciclo de ajustes da década de 1990 (BAUMANN, 2008).

A partir de 2003, o Brasil entra em uma senda de crescimento que vigora até a crise mundial, que tem início em meados de 2007. A partir de 2004, a estabilidade de preços, a consolidação dos resultados fiscais e um cenário externo favorável tiveram repercussão positiva sobre a geração de emprego e o investimento na economia brasileira (BAUMANN, 2008).

Outro fator que pode afetar a competitividade das empresas é a sua localização. De fato, a orientação produtiva de uma região, definida com base nas externalidades locais como a proximidade com os centros de consumo ou com os fornecedores de matéria-prima, tem um papel importante no resultado gerado nas empresas. Assim, empresas com elevados custos fixos costumam estar localizadas próximas dos seus fornecedores de matéria-prima (ALFRANCA e JUÁREZ, 2008). A proximidade com os mercados, a expansão da área metropolitana e a existência de economias externas de natureza territorial, como a localização, a urbanização e redes, podem converter-se em fatores territoriais de competitividade (TRULLÉN, LLADÓS e BOIX, 2002).

A economia da localização, gerada quando empresas de setores relacionados situam-se próximas umas das outras, também é um fator determinante na hora de definir a localização das empresas. Portanto, a escolha do local adequado para a instalação de uma fábrica pode resultar em vantagem competitiva. Desta forma, as ativi- dades demandantes de tecnologia avançada costumam situar-se em áreas com elevada economia de localização, ao passo que organizações tradicionais tendem a distribuir-se de forma mais dispersa (PABLO MARTÍ e MUÑOZ YEBRA, 2009). Variáveis como a qualidade da mão de obra, as ajudas e isenções públicas ou mesmo o relevo e o clima das regióes podem ajudar a definir a localizações das empresas (CUADRADO, MANCHA e GARRIDO, 1998).

A IAA encontra-se, em geral, condicionada pela localização dos grandes centros de consumo e das vias de comunicação, pois estes fatores representam oportunidades de economia de custos de transporte (MASCARAY, MEZA e ALBISU, 2001), além de poder influenciar na rentabilidade e crescimento das empresas (GONZÁLEZ e CORREA, 1998), ou na qualidade e preço dos produtos (ROMERO e SEPÚLVEDA, 1999).

Leva-se em consideração a definição de competitividade proposta por Chavarría et al. (2002):

“... competitividade é um conceito comparativo fundamental na capacidade dinâmica que tem uma cadeia agroalimentar localizada espacialmente, para manter, ampliar e melhorar de maneira contínua e sustentável sua participação no mercado, tanto doméstico como estrangeiro, por meio da produção, distribuição e venda de bens e serviços no tempo, lugar e forma solicitados, buscando como fim último o benefício da sociedade."

Neste sentido, é possível entender que a localização geográfica pode influenciar também a competitividade da IAA. Além disso, Delgadillo et al. (2006) argumentam que a localização resulta tão relevante como as vantagens operacionais em muitas empresas. Desta forma, o entorno onde a IAA desenvolve suas atividades pode configurar em vantagem competitiva dependendo de seus fatores internos, ou seja, os que são controláveis pela empresa, reduzindo custos de armazenagem ou influenciando no tamanho da indústria (SANJUÁN, MEZA e ALBISU, 2001).

Por sua vez, alguns autores indicam que a região onde está localizada a empresa e suas 
características geográficas, ambientais e culturais geram diferenças significativas no tamanho, rentabilidade e crescimento (DELGADILLO, TORRES e CORTÉZ, 2006; GALINDO, 2005; GONZÁLEZ e CORREA, 1998; ROMERO e SEPÚLVEDA, 1999). Também existem indícios da influência de que a localização geográfica pode chegar a ser um fator relevante na hora de explicar mudanças no crescimento de um setor regional (HERNÁNDEZ e PANIAGUA, 2008; MAYOR e LÓPEZ, 2008), ou favorecer o desenvolvimento de sistemas econômicos locais (ALBURQUERQUE, 2007; DONALD e BLAY-PALMER, 2006; PINGALI, 2006).

Ao mesmo tempo, Wilkinson (1995) aponta, de maneira geral, a redinamização do mercado alimentar com o aumento no valor agregado, diminuição no volume de matéria-prima incorporado e a demanda por novos produtos alimentícios como fatores que afetam a competitividade da IAA. Para o autor, a manutenção da competitividade do setor agroalimentar brasileiro exige novos padrões de regulação dos atores.

Diante da literatura consultada a respeito da localização e seu efeito na competitividade, o presente trabalho traz a seguinte hipótese:

- H1: As regiões onde estão localizadas as empresas podem apresentar efeitos que provocam diferenças na geração de postos de trabalho na IAA.

De acordo com Lamonica e Feijó (2011), a intensidade de mão de obra diminuiu de forma considerável entre 1970 e 2006, principalmente nas indústrias de transformação. Neste sentido, outra variável bastante discutida na literatura e abordada neste trabalho é o setor de atividades.

$\mathrm{O}$ mesmo pode influenciar na competitividade da IAA tanto nos fatores externos (entorno, ambiente político, legal, institucional, ambiente cultural e demográfico), quanto internos (condições de infraestrutura e ambiente tecnológico) (CHAVARRÍA, ROJAS e SEPÚLVEDA, 2002). Estes autores ressaltam ainda que as IAAs inseridas em um mesmo setor compartem características que podem chegar a condicionar sua competitividade.
Neste sentido, o trabalho propõe a seguinte hipótese relacionada ao efeito setor de atividade:

- H2: O número de pessoas ocupadas na IAA é resultado da competitividade entre os setores de atividade da IAA.

\section{Metodologia}

A análise shift share (SSA) foi desenvolvida por Dunn (1960), partindo da variação do emprego, como um método de determinação dos componentes que explicam as variações das magnitudes econômicas. A SSA permite desagregar as variações registradas em um período de tempo levado em consideração a região e o setor de atividades. A desagregação da SSA parte de uma variável econômica relevante, apresentando sua variação no período na forma de efeito total $\left(d_{\mathrm{ij}}\right)$. $\mathrm{O}$ método decompõe o efeito total em outros efeitos que guardam relação com a evolução econômica nacional $\left(n_{\mathrm{ij}}\right)$, com a estrutura produtiva da região $\left(e_{\mathrm{ij}}\right)$ e sua competitividade $\left(c_{\mathrm{ij}}\right)$ (MAYOR e LÓPEZ, 2008; RAMAJO e MÁRQUEZ, 2008; REIG, 2007).

A SSA tem sido bastante adotada em trabalhos que investigam a economia regional (ARCELUS, 1984; BROX e CARVALHO, 2008; ESTEBAN-MARQUILLAS, 1972; GARRIDO, 2002; MÁRQUEZ, RAMAJO e HEWINGS, 2009; MAUDOS, PASTOR e SERRANO, 2008; MAYOR e LÓPEZ, 2003; REIG, 2007), além de uma vasta aplicação em trabalho com foco no crescimento do emprego, levando em consideração as diferenças regionais e do setor de atividades (CÖRVERS e MERIKÜLL, 2007; EZCURRA e RAPÚN, 2006; EZCURRA et al., 2005; FOTOPOULOS, 2007; SUEDEKUM e LUDSTECK, 2006).

Ao mesmo tempo, a SSA foi criticada na área da investigação regional (GARRIDO, 2002; KNUDSEN e BARFF, 1991; WADLEY e SMITH, 2003). Estas críticas estão concentradas em dois argumentos: o primeiro de que o crescimento resultante da vinculação entre a indústria e os efeitos endógenos da competitividade não estão isolados, pelo contrário, estes se encontram inseridos no efeito competitivo; o segundo está 
relacionado com a instabilidade proveniente do tempo decorrente das mudanças da participação regional, além da variação deste componente entre as indústrias (ARCELUS, 1984; GARRIDO, 2002; HAYNES e DINC, 1997). Neste sentido, alguns autores propõem variações no modelo convencional da SSA, formulando alternativas que fizeram crescer a utilização do método a partir da solução destes problemas (ARCELUS, 1984; DINC, HAYNES e QIANGSHENG, 1998; DINC e HAYNES, 2005; ESTEBAN-MARQUILLAS, 1972; HAYNES e DINC, 1997).

Um dos trabalhos que primeiro realiza mudanças importantes na SSA é o de EstebanMarquillas (1972). O autor propõe a criação de dois novos efeitos que substituem o efeito competitivo $\left(c_{\mathrm{ij}}\right)$. Desta forma, Esteban-Marquillas remove do $c_{\mathrm{ij}}$ toda a influência da estrutura regional utilizando o efeito homotético que substitui a variação efetiva da variável estudada. Com isso, é possível decompor o efeito competitivo em dois subcomponentes que são denominados: participação regional ou efeito sobre a competência e efeito alocação. A participação regional mede as vantagens ou desvantagens do setor $j$ na região $i$ em relação com a zona de referência. O efeito alocação captura o grau geral da política regional de especialização no setor $j$ (ESTEBANMARQUILLAS, 1972).

Utilizando a proposta de Arcelus (1984) para o efeito competitivo considerando um setor $j$ e uma região $i$, podemos decompor a competitividade em um efeito competitivo de mercado e outro de especialização (ARCELUS, 1984; ESTEBANMARQUILLAS, 1972; REIG, 2007).

Vale ressaltar que, Arcelus (1984) faz importantes contribuições à SSA. O autor aborda o problema da instabilidade do componente de participação regional, antes mencionado. O modelo proposto por Arcelus (1984) decompõe cada um dos efeitos em um componente homotético e outro residual.

Levando em consideração as hipóteses deste trabalho, a SSA aparece como a ferramenta adequada para alcançar os objetivos propostos, pois permite decompor o resultado em efeitos como as diferenças da estrutura industrial (setores de atividades), assim como as vantagens ou desvantagens de uma determinada localização (região).

Para este trabalho foram utilizadas as seguintes notações na decomposição das variáveis da SSA: para os efeitos nacional $\left(n_{\mathrm{ij}}^{*} \mathrm{e} n^{* *} \mathrm{ij}\right)$, estrutural $\left(e^{*}{ }_{\mathrm{ij}}\right.$ e $\left.e^{* *}{ }_{\mathrm{ij}}\right)$, competitivo de mercado $\left(\mathrm{cm}_{\mathrm{ij}}^{*} \mathrm{e} c m^{* *}{ }_{\mathrm{ij}}\right)$ e competitivo de especialização $\left(c e^{*}{ }_{\mathrm{ij}}\right.$ e $c e^{* *}$ ij $)$. Esta desagregação da SSA é útil para compreender melhor as bases da competitividade regional nas atividades econômicas individuais (REIG, 2007).

A Tabela 2 apresenta o modelo proposto por Arcelus (1984), adotado neste trabalho. Com esta desagregação, espera-se identificar como os efeitos influem na variação do número de pessoas ocupadas na IAA brasileira no período de 1996 a 2012.

Tabela 2. Desagregação do modelo shift share análise

\begin{tabular}{|c|c|c|c|}
\hline Efeito Total $\left(E_{\mathrm{ij}}^{\mathrm{t}}-E^{\mathrm{t}-1}{ }_{\mathrm{ij}}\right)$ & Homotético & Residual & Total \\
\hline Efeito Nacional $\left(n_{\mathrm{ij}}\right)$ & $E^{t-1^{*}}{ }_{\mathrm{ij}} r_{00}$ & $\left(E^{\mathrm{t}-1 \mathrm{ij}}-E^{\mathrm{t}-{ }^{*}{ }_{\mathrm{ij}}}\right) r_{00}$ & $E^{\mathrm{t}-1}{ }_{\mathrm{ij}} r_{00}$ \\
\hline Efeito Estrutural $\left(e_{\mathrm{ij}}\right)$ & $E^{\mathrm{t}-1^{*}}{ }_{\mathrm{ij}}\left(r_{0 \mathrm{j}}-r_{00}\right)$ & $\left(E^{\mathrm{t}-1}{ }_{\mathrm{ij}}-E^{\mathrm{t}-1^{*}{ }_{\mathrm{ij}}}\right)\left(r_{0 \mathrm{j}}-r_{00}\right)$ & $E^{\mathrm{t}-1}{ }_{\mathrm{ij}}\left(r_{0 j}-r_{00}\right)$ \\
\hline Efeito Competitivo de Mercado $\left(\mathrm{cm}_{\mathrm{ij}}\right)$ & $E^{\mathrm{t}-1^{*}}{ }_{\mathrm{ij}}\left(r_{\mathrm{i} 0}-r_{00}\right)$ & $\left(E^{\mathrm{t}-1}{ }_{\mathrm{ij}}-E^{\mathrm{t}-\mathrm{-}^{*}}{ }_{\mathrm{ij}}\right)\left(r_{\mathrm{i} 0}-r_{00}\right)$ & $E^{\mathrm{t}-1}{ }_{\mathrm{ij}}\left(r_{\mathrm{i} 0}-r_{00}\right)$ \\
\hline Efeito Competitivo de Especialização $\left(c e_{\mathrm{ij}}\right)$ & $E^{\mathrm{t}-\mathrm{-}^{*}}{ }_{\mathrm{ij}}\left[\left(r_{\mathrm{ij}}-r_{\mathrm{i} 0}\right)-\left(r_{0 \mathrm{j}}-r_{00}\right)\right]$ & $\left(E^{\mathrm{t}-1}{ }_{\mathrm{ij}}-E^{\mathrm{t}-\mathrm{tij}^{*}}\right)\left[\left(r_{\mathrm{ij}}-r_{\mathrm{i} 0}\right)-\left(r_{0 \mathrm{j}}-r_{00}\right)\right]$ & $E^{\mathrm{t}-1} \mathrm{ij}_{\mathrm{j}}\left[\left(r_{\mathrm{ij}}-r_{\mathrm{i} 0}\right)-\left(r_{0 \mathrm{j}}-r_{00}\right)\right]$ \\
\hline
\end{tabular}

Fonte: Elaboração própria. 
Na desagregação adotada, o E representa a variável original na qual a SSA é realizada. Para este trabalho, o E representa o número de pessoas ocupadas na IAA entre 1996 e 2012 nos estados de Minas Gerais, Rio de Janeiro, São Paulo, Paraná, Santa Catarina e Rio Grande do Sul.

O efeito total $\left(d_{\mathrm{ij}}=E_{\mathrm{ij}}^{\mathrm{t}}-E^{\mathrm{t}-1}{ }_{\mathrm{ij}}\right)$ é a variação do número de pessoas ocupadas entre os anos $t$ e $t$-1 para a região $i$ e o setor $j$. O efeito nacional $\left(n_{\mathrm{ij}}=E^{\mathrm{t}-{ }^{*}{ }_{\mathrm{ij}} r_{00}}\right)$ reflete a variação que haveria ocorrido caso a IAA de cada setor e região mostrasse a mesma taxa de variação do total da IAA (CUADRADO, MANCHA e GARRIDO, 1998; DINC, HAYNES e QIANGSHENG, 1998; REIG, 2007). O $r_{00}$ representa a taxa de variação do número de ocupados a nível nacional.

O componente homotético $\left(n^{*}{ }_{\mathrm{ij}}=E^{\mathrm{t}-\mathrm{i}^{*}}{ }_{\mathrm{ij}} r_{00}\right)$ representa a variação do número de pessoas ocupadas caso não houvesse nenhuma mudança na IAA, em que $E^{t-{ }^{*}}{ }_{\mathrm{ij}} \mathrm{j}$ o volume teórico de ocupados que deveria gerar a região $i$ e o setor $j$ caso esta ponderação fosse a mesma obtida pelo total da IAA. O componente residual $\left(n^{* *}{ }_{i j}=\left(E^{\mathrm{t}-1}{ }_{\mathrm{ij}}-E^{\mathrm{t}-{ }^{*}{ }_{\mathrm{ij}}}\right) r_{00}\right)$ capta a variação devido à interação entre o efeito nacional e o setor refletindo o que ocorreu realmente (DINC, HAYNES e QIANGSHENG, 1998; KEIL, 1992).

O efeito estrutural $\left(e_{\mathrm{ij}}=E^{\mathrm{t}-1}{ }_{\mathrm{ij}}\left(r_{0 \mathrm{j}}-r_{00}\right)\right)$ aponta as diferenças entre uma região e a média devido à especialização produtiva (CUADRADO, MANCHA e GARRIDO, 1998). O $r_{0 j}$ é a taxa de variação de ocupados a nível nacional do setor de atividades $j$. $\mathrm{O} e_{\mathrm{ij}}$ permite analisar se a região está aumentando $\left(e_{\mathrm{ij}}>0\right)$ ou diminuindo $\left(e_{\mathrm{ij}}<0\right)$ o número de pessoas ocupadas em relação ao total da IAA. O signo positivo de $e_{\mathrm{ij}}$ indica que o modelo de especialização regional está voltado para setores dinâmicos da IAA, por outro lado, um $e_{\mathrm{ij}}$ negativo indica que a IAA da região não está especializada em setores que alcançam resultados maiores que os obtidos pelo total da IAA (DINC e HAYNES, 1999).

Ocomponentehomotético $\left[e_{\mathrm{ij}}^{*}=\left(E^{\mathrm{t}-1^{*}}{ }_{\mathrm{ij}}\left(r_{0 \mathrm{j}}-r_{00}\right)\right)\right]$ representa a variação do número de ocupados caso não houvesse ocorrido nenhuma mudança na IAA, supondo que houve um comporta- mento semelhante ao do total da IAA. O componente residual $\left[e^{* *}{ }_{\mathrm{ij}}=\left(E^{\mathrm{t}-1}{ }_{\mathrm{ij}}-E^{\mathrm{t}-{ }^{*}{ }_{\mathrm{ij}}}\right)\left(r_{0 \mathrm{j}}-r_{00}\right)\right]$ captura a variação derivada da interação entre a estrutura regional da IAA (DINC, HAYNES e QIANGSHENG, 1998; KEIL, 1992).

O efeito competitivo $\left(c_{\mathrm{ij}}\right)$ indica o desempenho relativo da indústria específica em uma região, portanto, reflete a vantagem competitiva diferencial (REIG, 2007). Neste trabalho foi adotada a desagregação proposta por Arcelus (1984), na qual o efeito competitivo está segmentado em dois outros efeitos: competitivo de mercado $\left(\mathrm{cm}_{\mathrm{ij}}\right)$ e competitivo de especialização $\left(c e_{\mathrm{ij}}\right)$. $\mathrm{O} c m_{\mathrm{ij}}$ reflete o impacto sobre o setor de atividade $\mathrm{j}$ da região i, sempre e quando a região obtenha uma variação positiva ou negativa diferente da nacional (REIG, 2007). O $r_{\mathrm{i} 0}$ é a taxa de variação do número de pessoas ocupadas na região $i$ a nível nacional. $\mathrm{O}$ componente homotético, $\left[\mathrm{cm}^{*}{ }_{\mathrm{ij}}=\left(E^{\mathrm{t}-\mathrm{1}^{*}}{ }_{\mathrm{ij}}\left(r_{\mathrm{i} 0}-r_{00}\right)\right)\right]$ busca capturar a parte do efeito total que pode ser atribuída ao crescimento da região. O componente residual, $\left[\mathrm{cm}^{* *}{ }_{\mathrm{ij}}=\left(E^{\mathrm{t}-1}{ }_{\mathrm{ij}}-E^{\mathrm{t}-\mathrm{1}^{*}}{ }_{\mathrm{ij}}\right) \times\left(r_{\mathrm{i} 0}-r_{00}\right)\right.$, busca capturar a parte do efeito total que pode ser atribuído à combinação da indústria regional (ARCELUS, 1984).

O efeito competitivo de especialização, $\left[c e_{\mathrm{ij}}=E^{\mathrm{t}-1}{ }_{\mathrm{ij}}\left[\left(r_{\mathrm{ij}}-r_{\mathrm{i} 0}\right)-\left(r_{0 \mathrm{j}}-r_{00}\right)\right]\right]$ busca identificar o papel que pode chegar a ter a especialização regional a respeito das atividades as quais a região tem vantagens competitivas. A variável $r_{\text {ij }}$ representa a taxa de variação de ocupados para a região $i$ e o setor $j$. $O c e_{i j}$ leva em consideração o comportamento relativo do conjunto da economia da região. Além disso, este efeito atribui a variação produzida à composição setorial da região (REIG, 2007), indicando, assim, se a região possui uma proporção relativamente grande de indústrias que estão obtendo uma variação positiva ou negativa ou que pode vir a se configurar em um efeito positivo ou negativo para as atividades industriais (DINC, HAYNES e QIANGSHENG, 1998). O valor positivo de $c e_{\mathrm{ij}}$ indica que existem vantagens comparativas na região e no setor $j$, enquanto que um signo negativo pode ser interpretado como evidência de que não existem tais vantagens (REIG, 2007). 
Para o efeito competitivo de especialização, foi utilizado na decomposição alternativa proposta por Arcelus (1984), no qual $c e_{\mathrm{ij}}$ é assim descrito: $E^{t-1}{ }_{\mathrm{ij}}\left[\left(r_{\mathrm{ij}}-r_{0 \mathrm{j}}\right)-\left(r_{\mathrm{i} 0}-r_{00}\right)\right.$. Desta forma, o efeito $\left(r_{\mathrm{i} 0}-r_{00}\right)$ foi descrito no $\mathrm{Cm}_{\mathrm{ij}}$; portanto, é necessário explicar o efeito [ $\left(r_{\mathrm{ij}}-r_{0 \mathrm{j}}\right)$, que indica o dinamismo do setor de atividade na região. $\mathrm{O}$ componente homotético $\left[c e^{*}{ }_{\mathrm{ij}}=E^{\mathrm{t}-{ }^{*}{ }_{\mathrm{ij}}}\left[\left(r_{\mathrm{ij}}-r_{\mathrm{i} 0}\right)-\left(r_{0 \mathrm{j}}-r_{00}\right)\right]\right]$ busca refletir a variação atribuída à estrutura setorial da região. Por sua vez, o componente residual $\left[c e^{* *}{ }_{\mathrm{ij}}=\left(E^{\mathrm{t}-1}{ }_{\mathrm{ij}}-E^{\mathrm{t}-{ }^{*}{ }_{\mathrm{ij}}}\right)\left[\left(r_{\mathrm{ij}}-r_{\mathrm{i} 0}\right)-\left(r_{0 \mathrm{j}}-r_{00}\right)\right]\right]$ tenta captar a variação obtida pela empresa em função da concentração setorial da região. Com esta decomposição, espera-se poder evidenciar a vantagem de determinada região a respeito da variação do número de ocupados na IAA.

\subsection{Variáveis e fonte dos dados}

No presente trabalho, foram utilizados os dados da população industrial ativa (PIA), disponíveis no Instituto Brasileiro de Geografia e Estatística (IBGE). A variável utilizada foi o pessoal ocupado em 31 de dezembro de cada ano consultado.
Devido às características dos dados disponíveis no IBGE, a amostra está formada por dois painéis de dados (1996-2007) e (2007-2012), com dados do número de pessoal ocupado segundo o Código de Atividade Econômica (CNAE) número 15 até 2007 e números 10 e 11 a partir de 2007, que correspondem à fabricação de produtos alimentícios e bebidas.

Os dados são referentes às empresas industriais com cinco ou mais pessoas ocupadas na amostra que compreende o período de 1996-2007 e empresas desde zero pessoas ocupadas para a amostra do período 2007-2012. A amostra está formada pelos estados de Minas Gerais, Rio de Janeiro, São Paulo, Paraná, Santa Catarina e Rio Grande do Sul. Segundo as notas técnicas (IBGE 2009), a variável pessoal ocupado total representa as pessoas efetivamente ocupadas em 31 de dezembro do ano de referência do Cadastro Central de Empresas (Cempre), incluindo pessoas assalariadas com e sem vínculo empregatício, bem como proprietários e sócios com atividade na unidade.

Os setores de atividades neste trabalho, segundo o CNAE, são os correspondentes à indústria agroalimentar. Neste sentido, este artigo adota os seguintes setores (Tabela 3):

Tabela 3. Classificação de atividades econômicas e as codificações que identificam cada setor de atividade

\begin{tabular}{cll}
\hline CNAE & \multicolumn{1}{c}{ Atividades } & Codificação \\
\hline 10.1 & Abate e preparação de produtos de carne e pescado & 101 - Carne \\
10.2 & Processamento, preservação e produção de conservas de frutas, legumes e outros vegetais & $102-$ Hortícola \\
10.3 & Produção de óleos e gorduras vegetais e animais & 103 - Óleos \\
10.4 & Laticínios & $104-$ Lácteos \\
10.5 & Moagem, fabricação de produtos amiláceos e de rações balanceadas para animais & $105-$ Amiláceo \\
10.6 & Fabricação e refino de açúcar & $106-$ Açúcar \\
10.7 & Torrefação e moagem de café & $107-$ Café \\
10.8 & Fabricação de outros produtos alimentícios & $108-$ Outros \\
10.9 & Fabricação de bebidas & 109 - Bebidas \\
\hline
\end{tabular}

Fonte: Elaboração própria a partir do CNAE. 


\section{Resultados e discussão}

O número de pessoas ocupadas no Brasil entre 1996 e 2012 cresceu na indústria extrativista e de transformação, contrariando o processo de redução da intensidade de mão de obra apresentado por Lamojica e Feijó (2011). Este fato pode ser explicado pelo aumento do número de empresas de menor tamanho nestes setores industriais, conforme aponta Sabóia (1999).

Neste período, a indústria alimentar, CNAE 10, aumentou o número de pessoas ocupadas. A IAA passou de uma posição relativa de $18 \%$ do número de trabalhadores do setor industrial para $20 \%$. O aumento foi de 859.420 novos postos de trabalho em 17 anos. Decompondo este resultado para cada um dos setores de atividade e as regiões, foi possível conhecer a importância da IAA na geração de ocupados no sudeste e sul do Brasil.

Os resultados do trabalho estão apresentados nas Tabelas 4 e 5 . Inicialmente é importante observar a taxa média de crescimento do número de ocupados na IAA no período de 1996-2012, que foi de $4 \%$ (Tabela 4 e Tabela 5). As regiões que apresentaram as maiores taxas de crescimento foram Santa Catarina com 7,1\%, seguida do Paraná com $5,1 \%$ e de São Paulo, com 4,9\%. Cabe ainda ressaltar que o Rio de Janeiro apresentou redução de $3 \%$ do número de ocupados no período.

Como o estado mais industrializado do País, São Paulo (SABÓIA, 2001), em números absolutos, é o principal gerador de emprego na IAA, com média de 373 mil empregos gerados por ano, seguido por Santa Catarina, com 134 mil empregos, e Paraná, com 87 mil.

Quanto aos setores de atividade (Tabela 5), destaca-se o setor de açúcar com crescimento de $7 \%$, seguido pelos setores de carne e hortícola, com $6,7 \%$ e $4,9 \%$, respectivamente.

De modo geral, os setores que superam a média na geração de postos de trabalho no período de 1996 a 2012 são carne (27\%), açúcar (19\%) e outros $(24 \%)$. Os setores de carne e açúcar indicam elevada importância na IAA uma vez que estes apresentam as maiores taxas de crescimento e o maior percentual de empregos, justamente por serem estas atividades intensivas em mão de obra como explicam Sesso Filho et al., (2010). Por sua vez, Wilkinson (1995) justifica os números apresentados pelo setor de carnes a partir do dinamismo do mercado doméstico de carne de frango, impulsionado por rápido declínio do preço relativo em relação a outras carnes.

Alguns estados apresentam concentração específica da sua IAA. São Paulo apresenta setores relevantes na geração de postos de trabalho para a IAA. Neste estado, os principais setores e sua participação são: carne (23\%), açúcar (20\%) e outros (26\%).

No estado de Minas Gerais, os setores com maior importância na geração de empregos são: carne $(20 \%)$, lácteos $(21 \%)$ e outros $(32 \%)$. Como apresentado na literatura, o setor lácteo é de grande relevância em Minas Gerais, sendo o estado responsável por 30\% do leite produzido no País (LEMOS et al., 2003), além da geração de emprego, renda e da conexão com outros setores agroindustriais (FERREIRA, ABRANTES e PEREZ, 2008).

No estado do Rio de Janeiro, os setores que superam a média da IAA na geração de postos de trabalho são: carne (18\%), outros (44\%) e bebidas (23\%). Aqui também encontramos um setor que se diferencia da IAA nacional.

Nos estados da região Sul, o setor de carne aparece em primeiro lugar devido ao crescimento de dois segmentos: a suinocultura e a avicultura com a integração entre criadores e os abatedouros (NOJIMA, 1999). Ao mesmo tempo, podem ser encontradas algumas diferenças da importância dos setores de atividade quanto ao pessoal ocupado nessa região. No Rio Grande do Sul, os setores que superam a média dos ocupados gerados na IAA são carne $(37 \%)$, amiláceos $(15 \%)$ e outros produtos $(24 \%)$.

No Paraná, o setor de amiláceos tem importante participação na geração de pessoal ocupado devido a sua especialização produtiva e processadora, respectivamente. Nojima (1999) ressalta que a concentração das indústrias ocorre devido à busca por vantagens competitivas, sejam elas a proximidade com os centros consumidores e/ou fontes de matéria-prima. Outro aspecto relacionado à competitividade que pode influenciar a IAA 

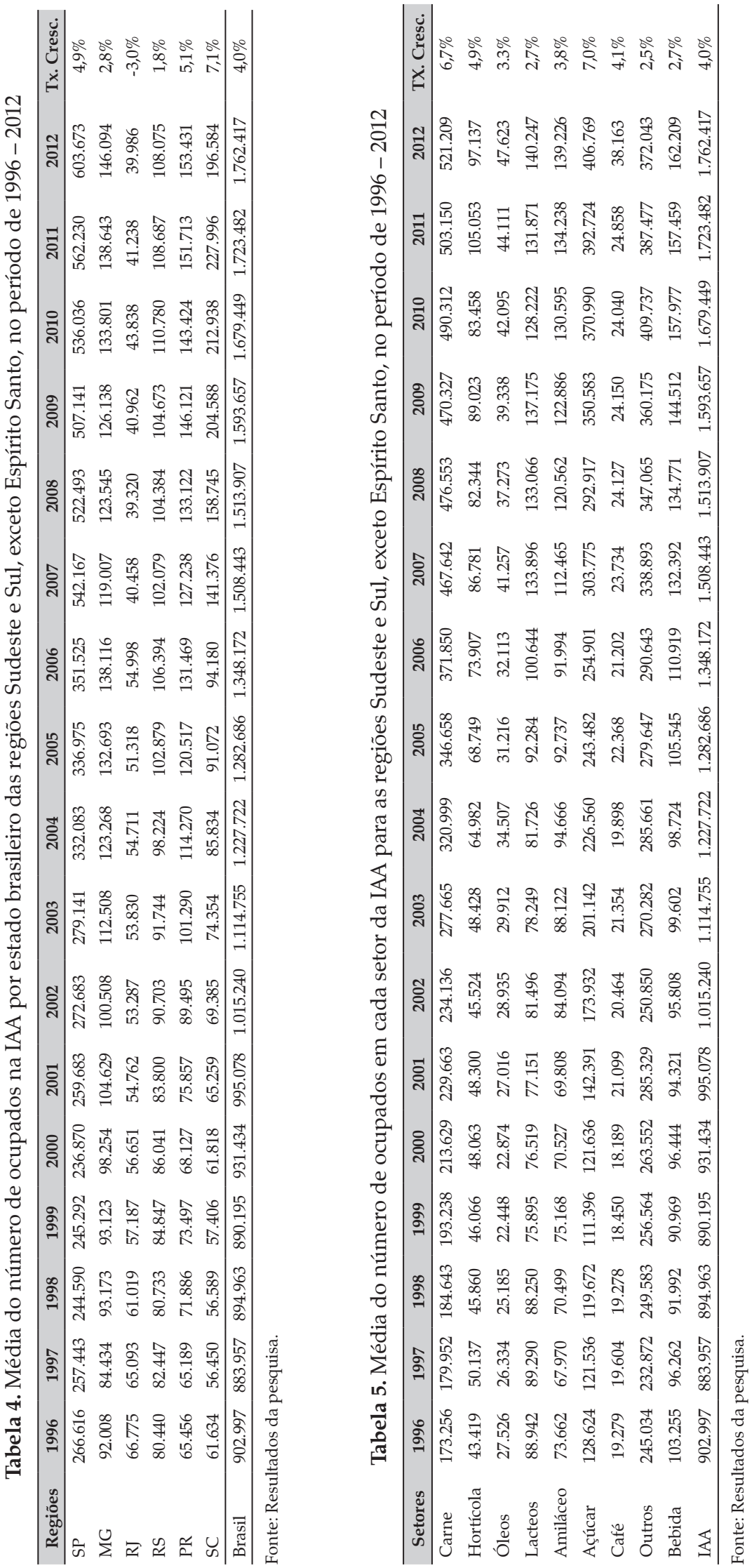
é a busca por atingir o mercado externo. Ainda no Paraná, os setores mais expressivos são carne (34\%), amiláceos (15\%) e outros (11\%) (NOJIMA, 1999); porém, a partir de 2002 este setor perde representatividade e o setor açúcar $(15 \%)$ passa a fazer parte do grupo de setores com geração de pessoal ocupado que supera a média. Desta forma, a IAA, no estado do Paraná, de certa forma, segue a concentração no número de pessoas ocupadas da IAA nacional.

Por sua vez, o estado de Santa Catarina tem sua IAA concentrada em dois setores de atividade. $\mathrm{O}$ setor carne representa mais de $70 \%$ dos ocupados no estado. O setor outros produtos alimentícios (14\%) também supera a média da IAA no estado.

A análise shift share permitiu decompor os dados e buscar uma explicação a respeito de quais efeitos (nacional, estrutural ou competitivo) são responsáveis pela geração de pessoas ocupadas na IAA. Neste sentido, a Figura 1 apresenta a variação do número de pessoas ocupadas para os estados de SP, MG, RJ, RS, PR e SC no período de 1996 a 2012.

A partir da Figura 1 fica evidente que a variação do número de pessoas ocupadas na IAA, nos estados de SP, MG, RJ, RS, PR e SC, é positiva por consequência do efeito nacional. Neste sentido, a variação no número de ocupados da IAA é deri- vada da evolução da economia como um todo, ou seja, o número de ocupados cresce devido à elevação da demanda (SESSO FILHO et al., 2010), da estabilidade da moeda (SILVA, 2003) e das ações para a geração de emprego por parte do governo federal. $\mathrm{O}$ resultado apresentado também indica uma pequena participação dos efeitos estrutural e competitivo no número de pessoas ocupadas nestes estados.

A variação apresentada, principalmente até o ano 2000, está apoiada nos argumentos de diversos autores como Baumann (2008), Lamonica e Feijó (2011), de que a indústria brasileira reagiu às mudanças econômicas da década de 1990, por meio de um processo de adaptação e modernização ajustando o quadro de funcionários, atualizando equipamentos, racionalizando custos, revendo a composição de produtos, logística e a equação energética.

Com uma indústria baseada em produtos básicos ou semimanufaturados, com pouco investimento em setores intensivos em tecnologia e de valor adicionado, os ajustes realizados ainda mantiveram o setor dependente dos termos de troca favoráveis, geralmente frutos da expansão na demanda internacional (LAMONICA e FEIJÓ, 2011).

Figura 1. Variação do número de pessoas ocupadas na IAA nos estados SP, MG, RJ, RS PR e SC e sua decomposição (SSA) no período de 1996-2012

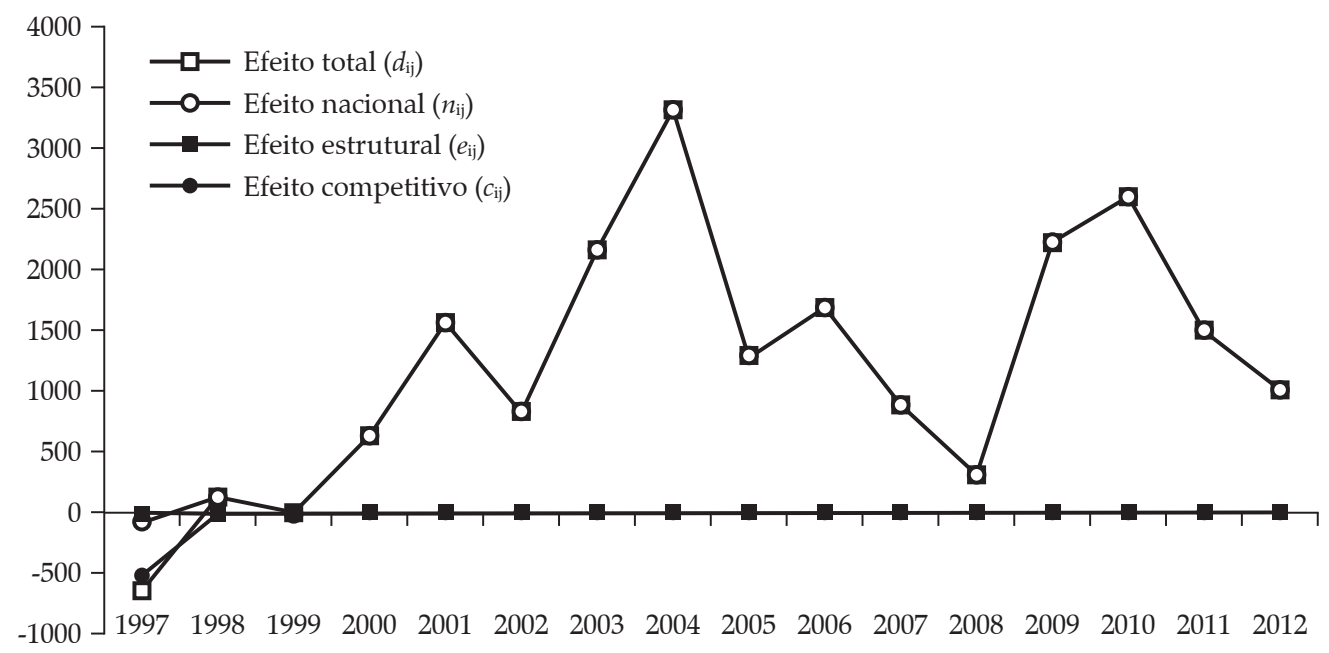

Fonte: Resultados da pesquisa. 
Figura 2. Decomposição do efeito nacional em homotético e residual

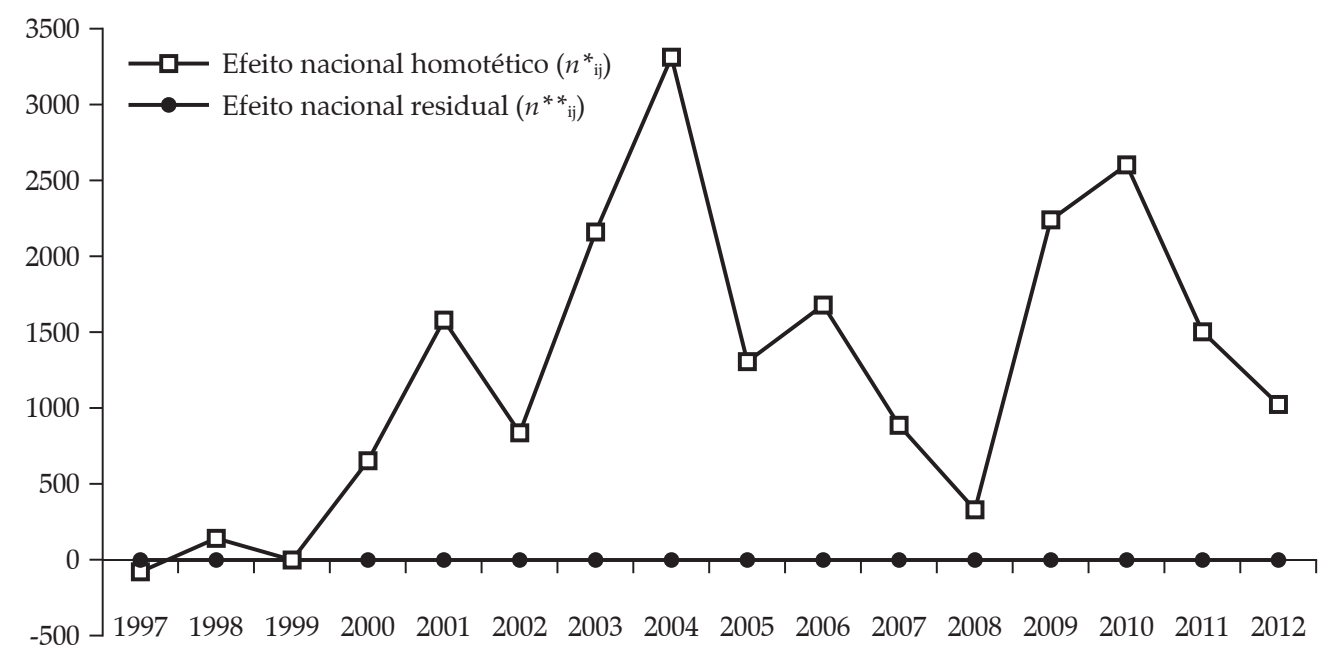

Fonte: Resultados da pesquisa.

Outro aspecto importante que dever ser considerado é o efeito do Programa Bolsa Família, vigente desde 2003, sobre a escolha ocupacional dos chefes de família beneficiários do programa. Barbosa e Corseuil (2011) apontam que o programa altera a escolha do tipo de trabalho elevando a taxa de trabalhadores informais. Ao mesmo tempo, o programa não incentiva a qualificação da força de trabalho para alcançar melhores posições no mercado de trabalho.

A Figura 2 apresenta a decomposição do efeito nacional em homotético $\left(n_{\mathrm{ij}}^{*}\right)$ e residual $\left(n^{* *}\right.$ ij $)$. Este resultado deixa evidente que a variação do número de ocupados da IAA, no período 1996-2012, segue o total da indústria nacional, não havendo uma diferença importante gerada exclusivamente pela IAA nos estados de SP, MG, RJ, PR, SC e RS. Neste sentido, o número de empregos gerados pela IAA no período foi consequência do crescimento do mercado nacional arrastado pela demanda internacional e não gerado por qualquer ação específica por parte da IAA.

A Figura 3 apresenta a decomposição do efeito estrutural em efeitos homotético $\left(e_{\mathrm{ij}}^{*}\right)$ e residual $\left(e^{* *}\right.$ ij). Nesta figura pode ser identificada a baixa variação do efeito estrutural, resultado que indica que a especialização produtiva das regiões estudadas não responde pela variação do número de ocupados da IAA. Portanto, é possível afirmar que as regiões não têm proporcionado efeitos que diminuam ou aumentem o número de ocupados.

Uma vez que o efeito estrutural não parece influenciar no número de pessoal ocupado na IAA, este resultado nos leva a rejeitar a hipótese de que a localização desta indústria gera diferenças de postos de trabalho. Este resultado difere do encontrado por Reig (2007), ao analisar as regiões espanholas, e nos leva a pensar que a IAA no Brasil está concentrada próxima dos centros produtivos em detrimento dos consumidores, uma vez que os dados analisados contemplam as regiões mais populosas do País.

A localização da IAA brasileira tem sentido quando analisada do ponto de vista da logística, uma vez que, em se tratando de produto com menor valor agregado, estar próximo dos centros de produção de insumo pode reduzir custos de operação e aumentar a margem das empresas. Ao mesmo tempo, a indústria de transformação reduziu, de maneira geral, a intensidade de mão de obra, como apontado por Lamonica e Feijó (2011), o que gerou um efeito estrutural insignificante do ponto de vista da geração de emprego. De fato, os autores afirmam que as mudanças 
recentes na estrutura produtiva não foram capazes de criar igualar a indústria brasileira com a de países industrializados.

O efeito competitivo e sua decomposição em homotético $\left(c^{*}{ }_{\mathrm{ij}}\right)$ e residual $\left(c^{* *}{ }_{\mathrm{ij}}\right)$, apresentados na Figura 4, indicam que o desempenho relativo do número de postos de trabalho gerados pela IAA praticamente não sofre efeito da vantagem competitiva da indústria.
Silva (2003) apontou uma redução da competitividade relativa da IAA no período de 1996 a 2006 devido também a mudanças na matriz produtiva e o foco em setores com maior valor agregado ou mesmo vinculados diretamente à vocação produtiva da região.

Lamojica e Feijó (2011) e Sabóia (2001) argumentam que a falta de investimento em setores intensivos em tecnologias e a concentração em

Figura 3. Decomposição do efeito estrutural em homotético e residual

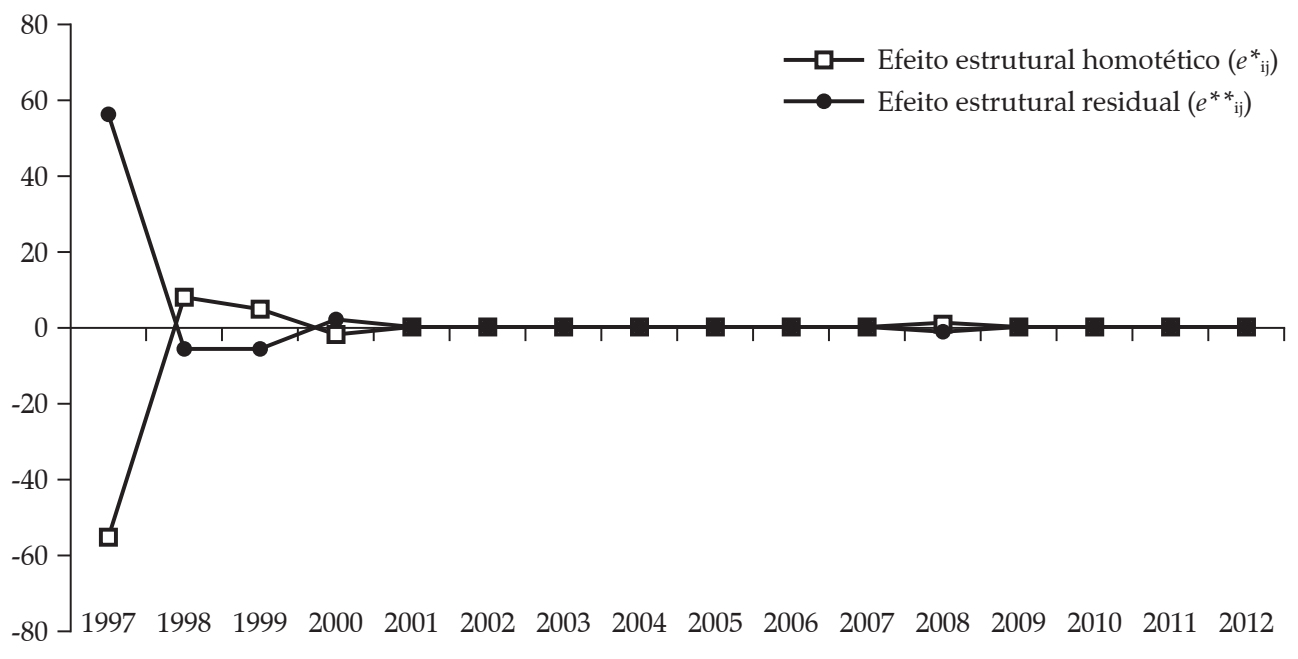

Fonte: Resultados da pesquisa.

Figura 4. Decomposição do efeito competitivo em homotético e residual

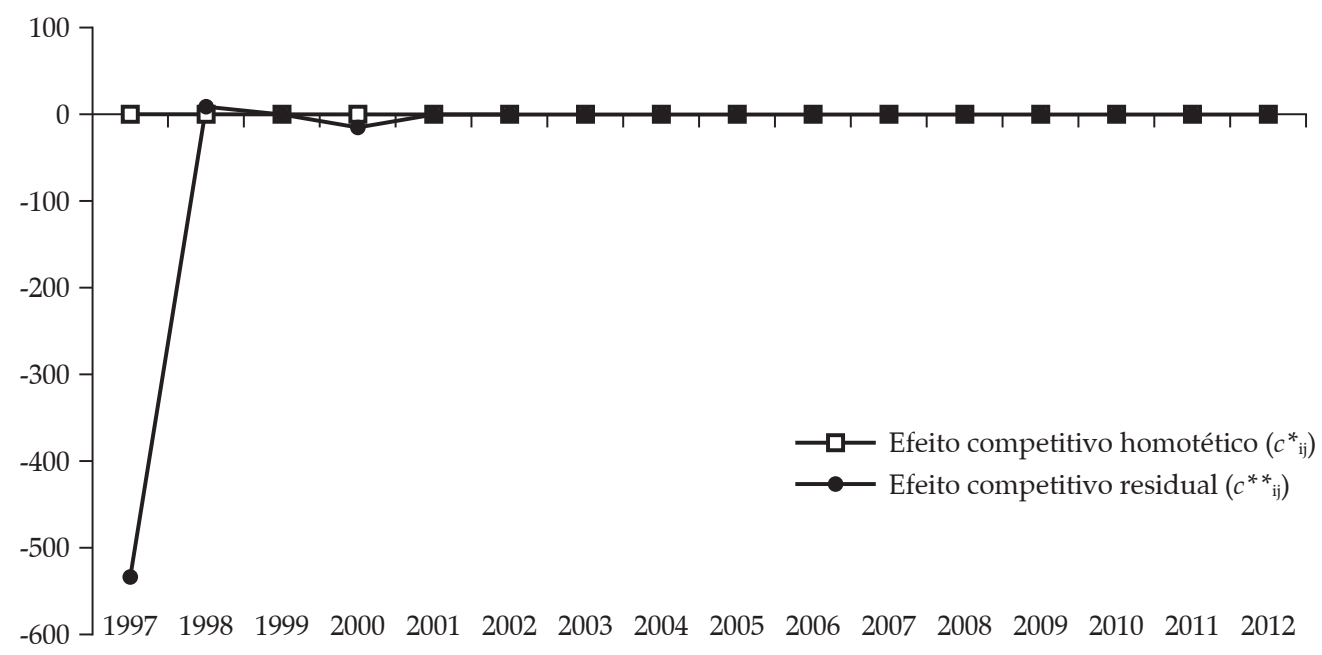

Fonte: Resultados da pesquisa. 
atividades de baixo valor adicionado são parte da causa para a falta de competitividade da indústria. Estes autores apontam ainda para a importância da especialização da indústria no sentido de alcançar uma produção com maior valor agregado, maior conteúdo tecnológico e dinamismo a ponto de contaminar outros setores da economia, para que então possa se construir uma indústria competitiva.

Desse modo, é possível rejeitar a hipótese de que a geração de emprego na IAA tem relação com a competitividade do setor industrial. Para identificar diferenças nos aspectos relacionados ao mercado e à especialização, seguiu-se a análise SSA proposta por Arcelus (1984), que decompõe o efeito competitivo em duas variáveis: competitivo de mercado $\left(c m_{\mathrm{ij}}\right)$ e de especialização $\left(c e_{\mathrm{ij}}\right)$. A Figura 5 apresenta a variação da IAA no período de 1996-2012 para $c m_{\mathrm{ij}}$ e $c e_{\mathrm{ij}}$ e seus componentes homotético e residual.

O impacto sobre os setores de atividades de cada região, representado pelo $\mathrm{cm}_{\mathrm{ij}}$, não mostra uma variação relevante no caso da IAA. Este resultado indica que os setores de atividades na IAA dos estados de SP, MG, RJ, RS, PR e SC não afetam, positiva ou negativamente, a variação do número de postos de trabalho na IAA.
Por sua vez, a especialização regional, representada por $c e_{\mathrm{ij}}$, apresenta uma variação que parece influenciar no número de pessoas ocupadas da IAA. As decomposições homotética $\left(c e^{*}{ }_{\text {ij }}\right)$ e residual $\left(c e^{* *}{ }_{\mathrm{ij}}\right)$ indicam que a especialização regional poderia ter sido um efeito positivo, pelo menos nos anos 2003, 2007, 2010 e 2012, como indica o efeito homotético; porém, de acordo com o efeito residual, ela realmente teve um efeito negativo na variação do emprego gerado pela IAA.

Este resultado é corroborado pelo trabalho de Lamonica e Feijó (2011), no qual os autores apontam a redução na intensidade de mão de obra e as mudanças estruturais que não trouxeram os efeitos esperados para a indústria brasileira.

A recente pesquisa realizada pela Boston Consulting Group (BCG) reforça os resultados relacionados à competitividade da IAA, uma vez que aponta que a competitividade da indústria brasileira permanece inferior quando comparada com a de outros países em desenvolvimento, devido à dificuldade para fazer negócios, à qualidade da mão de obra ou ao número de horas demandadas para cumprir obrigações tributárias (SIRKIN, ZINSER e ROSE, 2014).

Dentre as variáveis consideradas pela BCG (salário na indústria, produtividade, custo da

Figura 5. Decomposição do efeito competitivo de mercado e de especialização em homotético e residual

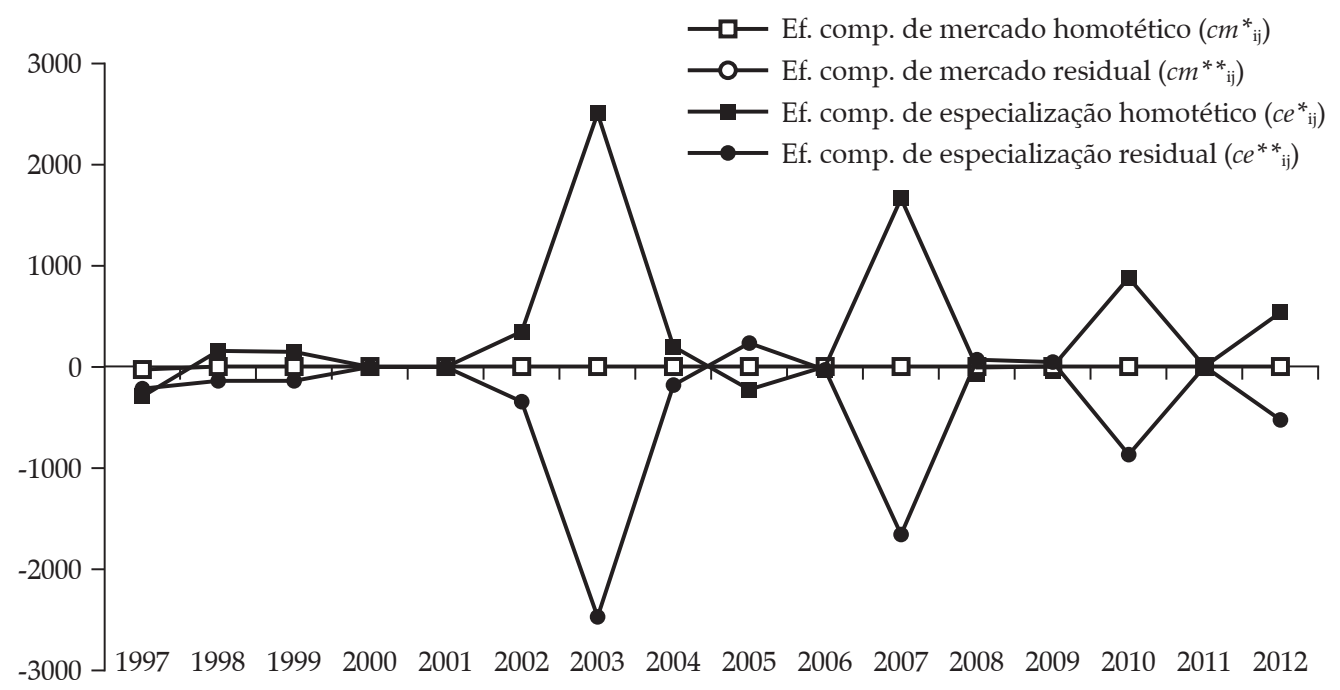

Fonte: Resultados da pesquisa. 
energia e taxa de câmbio), o Brasil apresentou piora nos últimos 10 anos para todas elas, fato que dificulta a disputa no mercado internacional e perda de espaço também no mercado interno (SIRKIN, ZINSER e ROSE, 2014). É de se esperar que, com a elevação do custo da mão de obra, este reflita na variação do número de pessoal ocupado na IAA, como indicam nossos resultados.

\section{Considerações finais}

No Brasil, a indústria de transformação é o segundo segmento em importância quando é levado em consideração o número de pessoal ocupado, atrás apenas do setor automobilístico. A indústria agroalimentar, especificamente, tem um papel importante neste sentido atuando como motora do setor rural. No presente trabalho, foi possível identificar que a IAA obteve uma variação positiva no número de postos de trabalho gerados, no período de 1996 até 2012, apesar da redução apresentada pelo total do setor industrial. Esta variação ocorreu inclusive nos momentos em que o País passou por crises. Neste sentido, fica indicada a solidez da IAA enquanto setor industrial gerador de emprego, uma vez que esta indústria não apresenta importantes variações, apesar dos momentos de recessão econômica.

A hipótese de que a localização das empresas afetaria o número de ocupados demonstrou não ser verdadeira para a IAA brasileira. Esta variação, pelo menos nos estados de São Paulo, Minas Gerais, Rio de Janeiro, Rio Grande do Sul, Paraná e Santa Catarina, mostrou ser derivada do efeito nacional e não da estrutura da indústria ou da competitividade da mesma. Assim, a variação no número de ocupados na IAA é decorrente do aumento do salário, do modelo dirigido pela demanda e pelo consumo, do aumento do crédito, enfim, do crescimento geral do País.

A competitividade da IAA também mostrou ser outra variável que não afeta a variação do número de ocupados da IAA. Neste sentido, fica indicada uma lacuna na IAA que precisa ser solucionada buscando-se alcançar vantagens com- petitivas que permitam a ela se diferenciar nos mercados nacional e internacional.

Por último, porém não menos importante, cabe ressaltar que os investimentos públicos para atrair as indústrias do setor alimentar representam o principal efeito na geração de emprego. Dessa forma, cabe um estudo para quantificar este esforço público na geração de postos de trabalho no sentido de medir sua efetividade.

\section{Referências}

ABIA. A Força do Setor de Alimentos. Disponível em: $<$ http://abia.org.br/vst/AForcadoSetordeAlimentos. pdf $>$. Acesso em: 16 ago. 2014.

ALBURQUERQUE, F. L. Desarrollo económico y territorio: Enfoques teóricos relevantes y reflexiones derivadas de la práctica. In: GARCÍA, M. D. (Ed.). Perspectivas teóricas en Desarrollo Local. La Coruña: Ed. Netbiblo, 2007. p. 59-76.

ALFRANCA, O. e JUÁREZ, M. I. Concentración de la innovación y empresa agroalimentaria. Economia Industrial, v. 368, p. 141-153, 2008.

ARCELUS, F. J. An extension of shift-share analysis. Growth and Change, v. 15, n. 1, p. 3-8, 1984.

BARBOSA, A. L. N. de H. Evolução e composição do emprego no Brasil: Período 1996-2009. Boletim Mercado de Trabalho - Conjuntura e Análise, v. 50, p. 41-48, 2012.

. e CORSEUIL, C. H. L. Bolsa família, escolha ocupacional e informalidade no Brasil. Mercado de Trabalho Conjuntura e Análise, v. 47, p. 29-36, 2011.

BARRETO, R. S. et al. Uma análise sobre o emprego setorial brasileiro. Revista de Economia e Agronegócio, v. 8, n. 1, p. 27-50, 2010.

BAUMANN, R. Emprego, desenvolvimento humano e trabalho decente: a experiêcia brasileira recente (CEPAL, Ed.). Brasília: CEPAL/PNUD/OIT, 2008.

BID, B. I. DE D. Competitividad: el motor del crecimiento : progreso económico y social en América Latina: informe 2001. [s.1.] Banco Interamericano de Desarrollo, 2001.

BROX, J. A. e CARVALHO, E. A demographically augmented shift-share employment analysis: an application to canadian employment patterns. The Journal of Regional Analysis \& Policy, v. 38, n. 2, p. 56-66, 2008. 
CHAVARRÍA, H., ROJAS, P. e SEPÚLVEDA, S. G. Competitividad: elementos conceptuales. [s.l.] IICA, 2002.

CÖRVERS, F. e MERIKÜLL, J. Occupational structures across 25 EU countries: the importance of industry structure and technology in old and new EU countries. Economic Change, v. 40, p. 327-359, 2007.

CUADRADO, J. R. R., MANCHA, T. N. e GARRIDO, R. Y. Convergencia regional en España: hechos, tendencias y perspectivas. Madrid: Fundación Argentaria, 1998. v. 8

DELGADILLO, J. M., TORRES, F. T. e CORTÉZ, H. M. Y. Nuevas opciones para generar empleos e ingresos en el medio rural (IICA, Ed.)Cuaderno Técnico de Desarrollo Rural. San José: Instituto Interamericano de Cooperación para la Agricultura, 2006.

DINC, M., HAYNES, K. E. e QIANGSHENG, L. A Comparative evaluation of shift-share models and their extensions. Australian Journal of Regional Studies, v. 4, n. 2, p. 275-302, 1998.

.eHAYNES, K.E. Sources of regionalinefficiency: An integrated shift-share, data envelopment analysis and input-output approach. The Annals of Regional Science, v. 33, p. 469-489, 1999.

. e HAYNES, K. E. Productivity, International Trade and Reference Area Interactions in Shift-Share Analysis: Some Operational Notes. Growth and Change, v. 36, n. 3, p. 374-394, 2005.

DONALD, B. e BLAY-PALMER, A. The urban creativefood economy: producing food for the urban elite or social inclusion opportunity? Environment and Planning, v. 38, p. 1901-1920, 2006.

DUNN, E. S. A statistical and analytical technique for regional analysis. Papers of the Regional Science Association, v. 6, p. 97-112, 1960.

ESTEBAN-MARQUILLAS, J. M. Shit-and Share Analysis Revisited. Regional and Urban Economics, v. 2, n. 3, p. 249-255, 1972.

EZCURRA, R. et al. Regional Inequality in the European Union: Does Industry Mix Matter? Regional Studies, v. 39, n. 6, p. 679-697, 2005.

e RAPÚN, M. Regional Disparities and National Development Revisited the Case of Western Europe. European Urban and Regional Studies, v. 13, n. 4, p. 355-369, 2006.

FERREIRA, M. A. M., ABRANTES, L. A. e PEREZ, R. Investigação de grupos estratégicos na indústria de laticínios por meio da abordagem multivariada. Revista de Administraçao Mackenzie, v. 9, n. 2, p. 152-172, 2008.
FILHO, N. A. M., CABANAS, P. H. F. e KOMATSU, B. K. Tendências recentes do mercado de trabalho brasileiro. Boletim Mercado de Trabalho - Conjuntura e Análise, v. 56, p. 67-76, 2014.

FILHO, P. J. M., SCHUMACHER, G. e REICHERT, H. Especialização, emprego e vantagem competitiva nos setores econômicos do Rio Grande do Sul: Governos de FHC e Lula. Análise, v. 22, n. 1, p. 89-100, 2011.

FISCHER, C. e SCHORNBERG, S. Assessing the Competitiveness Situation of EU Food and Drink Manufacturing Industries: An Index-Based Approach. Agribusiness, v. 23, n. 4, p. 473-495, 2007.

FOTOPOULOS, G. Integrating Firm Dynamics into the Shift-Share Framework. Growth and Change, v. 38, n. 1, p. 140-152, 2007.

GALINDO, A. L. El tamaño empresarial como factor de diversidad. Madrid: [s.n.].

GARRIDO, R. Y. Cambio estructural y desarrollo regional en España. Madrid: [s.n.].

GONZÁlEZ, A. L. P. e CORREA, A. R. Crecimiento y Tamaño un estudio empirico. Revista Española de Financiación y Contabilidad, v. XXVII, n. 95, p. 541-573, 1998.

HAYNES, K. E. e DINC, M. Productivity Change in Manufacturing Regions: A Multifactor/Shift-Share Approach. Growth and Change, v. 28, p. 201-221, 1997.

HERNÁNDEZ, J. R. e PANIAGUA, M. Á. M. Componentes espaciales en el modelo Shift-Share. Una aplicación al caso de las regiones peninsulares españolas. Estadística Española, v. 50, n. 168, p. 247-272, 2008.

KEIL, S. R. On the Value of Homotheticity in the Shift-Share Framwork. Growth and Change, v. 23, n. 4, p. 469-493, 1992.

KNUDSEN, D. C. e BARFF, R. Shift-share analysis as a linear model. Environment and Planning A, v. 23, n. 3, p. 421-431, 1991.

KRUGMAN, P. Competitiveness: a dangerous obsession. Foreing Affairs, v. 73, n. 2, p. 28-44, 1994.

LAMONICA, M. T. e FEIJÓ, C. A. Crescimento e industrialização no Brasil: uma interpretação à luz das propostas de Kaldor. Revista de Economia Política, v. 31, n. 1 (121), p. 118-138, 2011.

LEITE, C. H. C. et al. Análise do Mercado de Trabalho. Mercado de Trabalho Conjuntura e Análise, v. 59, n. 21, p. 1-23, 2015.

LEMOS, M. B. et al. Tecnologia, especialização regional e produtividade: um estudo da pecuária leiteira em 
minas Gerais. Revista de Economia e Socilogia Rural, v. 41, n. 3, p. $117-138,2003$.

LÓPEZ, A. M. G., MÉNDEZ, J. J. e DONES, M. T. Factores clave de la competitividad regional: innovación e intangibles. Información Comercial Española, ICE: Revista de economía, n. 848, p. 125-140, 2009.

MÁRQUEZ, M. A., RAMAJO, J. e HEWINGS, G. J. D. Incorporating Sectoral Structure into Shift-Share Analysis. Growth and Change, v. 40, n. 4, p. 594-618, 2009.

MASCARAY, M. Á., MEZA, L. e ALBISU, L. M. La localización de la industria agroalimentaria en la Rioja: Núcleos rurales versus núcleos urbanos. Berceo, v. 141, p. 229-246, 2001.

MAUDOS, J., PASTOR, J. M. e SERRANO, L. Explaining the US-EU productivity growth gap: Structural change vs. intra-sectoral effect. Economics Letters, v. 100, p. 311-313, 2008.

MAYOR, M. e LÓPEZ, A. J. La Dinámica Regional del Empleo. Una aproximación basada en análisis Shift Share Estocástico Anales de economía aplicada. Almeria, 2003.

. e LÓPEZ, A. J. Spatial shift-share analysis versus spatial filtering: an application to Spanish employment data. Empirical Economics, v. 34, p. 123-142, 2008.

MONTE, P. A. do, RAMALHO, H. M. de B. e PEREIRA, M. de L. O salário de reserva e a oferta de trabalho: evidências para o Brasil. Economia Aplicada, v. 15, n. 4, p. 613-639, 2011.

NOJIMA, D. Panorama, tendências e competitividade da industria de alimentos e de bebidas no Paraná. Revista Paranaense de Desenvolvimento, v. 95, p. 79-87, 1999.

PABLO MARTÍ, F. e MUÑOZ YEBRA, C. Localización empresarial y economías de aglomaración: el debate en torno a la agregación espacial. Investigaciones Regionales, v. 1, p. 139-166, 2009.

PINGALI, P. Agricultural Growth and Economic Development: A View through the Globalisation Lens (G. Coast, Ed.). Agricultural Growth and Economic Development: A View through the Globalisation Lens. Australia, 2006.

POCHMANN, M. Emprego, desenvolvimento humano e trabalho decente. In: Emprego, desenvolvimento humano e trabalho decente: a experiência brasileira recente. [s.l: s.n.]. p. 76-97.

RAMAJO,J.H.; MÁRQUEZ,M. ÄNGEL P.Componentes espaciales en el modelo Shift-Share. Una aplicación el caso de las regiones peninsulares españolas. Estadística Española, v. 50, n. 168, p. 247-272, 2008.

REIG, E. M. Competitividad, crecimiento y capitalización de las regiones españolas. Bilbao: [s.n.].

ROMERO, S. e SEPÚLVEDA, S. Territorio, agricultura y competitividad (IICA, Ed.). Cuadernos Técnicos. San José: Instituto Interamericano de Cooperación para la Agricultura, 1999.

ROMO, D. M. e ABDEL, G. M. Sobre o concepto de competitividad. Comercio Exterior, v. 55, p. 200-214, 2005.

SABÓIA, J. Modernização e redução do tamanho dos estabelecimentos da indústria de transformação no passado recente. Econômica, v. 1, n. 1, p. 53-74, 1999.

Emprego industrial no Brasil: situação atual e perspectivas para o futuro. Revista de Economia Contemporânea, v. 5, p. 207-229, 2001.

SANJUÁN, A. I., MEZA, L. e ALBISU, L. M. La dimensión como condicionante de las estratégias competitivas de las empresas agroalimentariasIV Congreso Nacional de Economía Agraria. Pamplona, 2001.

SESSO FILHO, U. A. et al. Decomposição estrutural da variaçao do emprego no Brasil, 1991-2003. Economia Aplicada, v. 14, n. 1, p. 99-123, 2010.

SILVA, C. A. B. da, BATALHA, M. O. Competitividade em Sistemas Agroindustriais: Metodologia e Estudos de Caso. II Workshop Brasileiro de GEstão de Sistemas Agroalimentares. Anais... Ribeirão Preto: PENSA/FEA/ USP, 1999

SILVA, I. L. Disparidades, Competitividad Territorial y Desarrollo Local y Regional en América Latina. Ilustrada ed. Santiago de Chile: [s.n.].

SIRKIN, H. L., ZINSER, M. e ROSE, J. R. The Shifting Economics of Global Manufacturing: how cost competitiveness is changing wordwide. [s.l: s.n.].

SUEDEKUM, J. e LUDSTECK, J. What has caused regional employment growth differences in Eastern Germany? Jahrbuch für Regional wissenschaft, v. 26, p. $51-73,2006$.

TRULLÉN, J., LLADÓS, J. e BOIX, R. Economía del conocimiento, ciudad y competitividad. Investigaciones Regionales, v. 1, p. 139-161, 2002.

WADLEY, D. e SMITH, P. Straightening up shift-share analysis. The Annals of Regional Science, v. 37, p. 259-261, 2003.

WILKINSON, J. Competitividade da agroindústria brasileira. Agricultura em São Paulo, v. 42, n. 1, p. 27-56, 1995. 


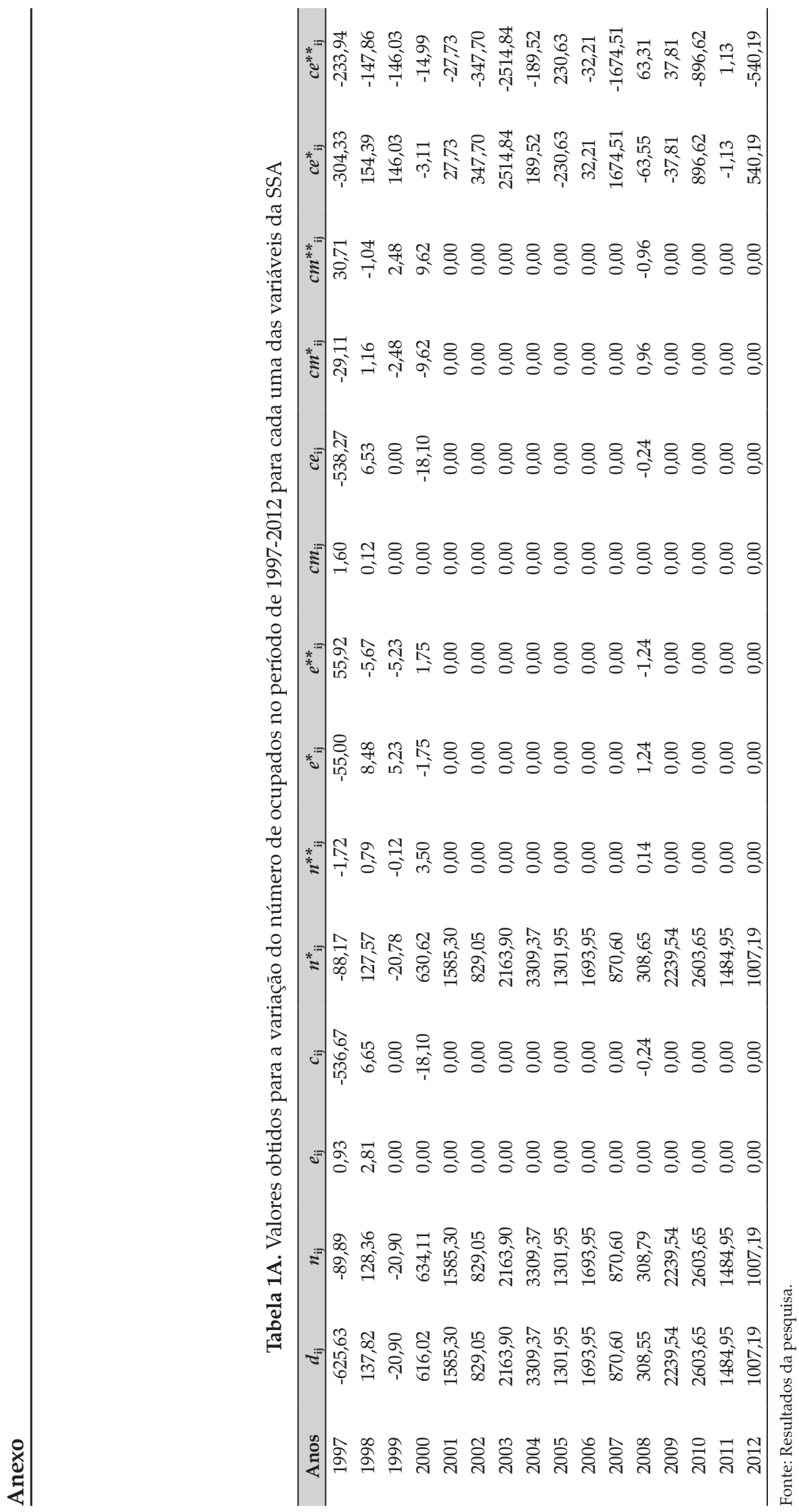

